\title{
Parâmetros Ruminal, Sangüíneo e Urinário e Digestibilidade de Nutrientes em Novilhas Leiteiras Recebendo Diferentes Níveis de Monensina
}

\section{Marcus Vinicius Morais de Oliveira1, Rogério de Paula Lana ${ }^{2}$, Acyr Wanderley de Paula Freitas ${ }^{3}$, Eduardo da Costa Eifert ${ }^{4}$, José Carlos Pereira ${ }^{2}$, Sebastião de Campos Valadares Filho ${ }^{2}$, Juan Ramon Olaquiaga Pérez ${ }^{5}$}

\begin{abstract}
RESUMO - Objetivou-se verificar a influência da inclusão de diferentes níveis do ionóforo monensina sódica na dieta sobre os parâmetros ruminal, sangüíneo e urinário e a digestibilidade aparente em novilhas leiteiras. Foram coletadas amostras de líquido ruminal (imediatamente antes e duas horas após a alimentação), sangue, urina e fezes de 28 novilhas da raça Holandesa mantidas em regime de confinamento por 84 dias. As dietas possuíam 32,84\% de concentrado (grão de milho, farelo de soja, uréia e mistura mineral), 33,58\% de silagem de milho e 33,58\% de cana-de-açúcar na matéria seca. Os níveis de ionóforo avaliados foram 0, 14, 28 e $42 \mathrm{mg}$ de monensina/kg de matéria seca da dieta. O experimento foi instalado conforme delineamento inteiramente casualizado, com quatro tratamentos e sete repetições, realizando-se estudos de regressão e contrastes ortogonais. Antes da alimentação, a monensina não influenciou o pH ruminal e a concentração de amônia e dos ácidos acético, propiônico e butírico, mas promoveu redução da relação acetato:propionato. Duas horas após a alimentação, verificou-se redução do pH e da relação acetato:propionato; e aumento da concentração de ácido propiônico. O estudo de contrastes revelou que ocorreu diminuição da concentração de amônia antes da alimentação. Não foram verificadas mudanças significativas nas concentrações de glicose e uréia sangüínea. A monensina também não influenciou os consumos de matéria seca(MS), matéria orgânica, proteína bruta, extrato etéreo(EE), carboidratos totais (CHOT) e fibra em detergente neutro. As digestibilidades da MS, EE e CHOT e a perda de nitrogênio urinário apresentaram respostas quadráticas.
\end{abstract}

Palavras-chave: ácidos graxos voláteis, amônia, ionóforo, rúmen

\section{Effects of Different Dietary Levels of Monensin on Nutrient Digestibility and on Ruminal, Blood and Urinary Metabolites in Dairy Heifers}

\begin{abstract}
The objective of this trial was to study the effects of different dietary levels of the ionophore monensin on apparent digestibility of nutrients and on ruminal, blood, and urinary metabolites in dairy heifers. Samples of ruminal fluid (pre-feeding and 2 hours post-feeding), blood, urine, and feces all were collected from 28 confined Holstein heifers. Diets contained (dry matter basis): $32.84 \%$ of concentrate (corn grain, soybean meal, urea, and mineral salt mixture), $33.58 \%$ of corn silage, and $33.58 \%$ of sugarcane. The following amounts of monensin were included in the diets: $0,14,28$ or $42 \mathrm{mg} / \mathrm{kg}$ of diet dry matter. The experiment was analyzed as a complete randomized design with four treatments and seven replications. Both regression analysis and orthogonal contrasts were part of the statistical model. No significant differences before feeding were observed for ruminal $\mathrm{pH}$ and for the ruminal concentrations of ammonia, acetate, propionate, and butyrate by adding monensin to the diets. However, a significant reduction in the acetate:propionate ratio was detected. Conversely, ruminal $\mathrm{pH}$ decreased and ruminal propionate increased when samples were taken at two hours after feeding. As before, the acetate:propionate ratio was reduced when monesin was increased from 0 to $42 \mathrm{mg} /$ $\mathrm{kg}$ of diet dry matter. In addition, orthogonal contrasts showed a decrease in the concentration of ruminal ammonia before feeding. Including monesin in diet of dairy heifers did not alter the concentrations of glucose and blood urea. Similarly, intakes of dry matter (DM), organic matter, crude protein, ether extract (EE), total carbohydrates (TC), and neutral detergent fiber were all unchanged by dietary supplementation with monensin. Significant quadratic effects were observed for apparent digestibilities of DM, EE, and TC and also for the excretion of urinary nitrogen.
\end{abstract}

Key Words: ammonia, ionophore, rumen, volatile fatty acids

\section{Introdução}

Ionóforos são produtos da fermentação de vários actinomicetos, produzidos principalmente por bactérias do grupo Streptomyces cinnamonensis (Haney \& Hoehn, 1967). Existem atualmente mais de 70 tipos de ionóforos identificados, que agem como um aditivo melhorador da eficiência alimentar em ruminantes, por meio da redução do consumo de alimentos em animais confinados. No Brasil, somente os ionóforos monensina sódica e lasalocida sódica receberam aprovação para serem incluídos na dieta de ruminantes. A

\footnotetext{
${ }^{1}$ Professor - Departamento de Zootecnia/UEMS - Rodovia Aquidauana/CERA km 12 - Zona Rural, Aquidauana-MS. CEP 79.200.000 (marcusvmo@yahoo.com.br).

2 Professor - Departamento de Zootecnia/UFV, Viçosa-MG, CEP: 36.571-000; Bolsista do CNPq.

3 Pesquisador do Instituto de Zootecnia (apfreitas@aptaregional.sp.gov.br).

4 Post-Doc ESALQ-USP, bolsista FAPESP (eifert@esalq.usp.br).

5 Professor - Departamento de Zootecnia/UFLA, Lavras-MG.
} 
melhoria da eficiência alimentar está relacionada, segundo Russell (1996), às propriedades químicas dos ionóforos, ou seja, à alta hidrofobicidade, associada à elevada capacidade ligante a prótons, permitindo que ajam como dissipadores de gradiente de íons através da membrana celular de bactérias gram-positivas e de certas classes de protozoários e fungos, afetando negativamente o desenvolvimento destes microrganismos e, conseqüentemente, a fermentação e os produtos finais da digestão microbiana.

A maior fragilidade das bactérias gram-positivas aos ionóforos se deve à estrutura física de sua membrana celular. De acordo com Russell \& Wallace (1997), além da membrana celular interna, as bactérias gram-negativas possuem mais duas membranas, uma delgada formada por peptidioglicanos e, mais externamente, uma formada por proteínas, lipoproteínas e lipopolissacarídeos, impermeável às grandes moléculas da monensina. Essa estrutura física faz com que a membrana celular interna fique protegida e que as bactérias gram-negativas, conseqüentemente, sejam resistentes aos ionóforos. As bactérias gram-positivas, por sua vez, possuem, além da membrana celular interna, apenas uma membrana externa formada por peptidioglicanos, que, apesar de espessa, é porosa e não consegue impedir a ação da monensina, o que as tornam sensíveis aos ionóforos. Protozoários e fungos não possuem a membrana protetora externa e também são sensíveis à monensina quando avaliados em experimentos in vitro (Dennis et al., 1986).

Os principais produtos da fermentação microbiana ruminal são os ácidos acético, propiônico e butírico, a amônia $\left(\mathrm{NH}_{3}\right)$, o dióxido de carbono $\left(\mathrm{CO}_{2}\right)$ e o metano $\left(\mathrm{CH}_{4}\right)$. O dióxido de carbono e o metano são produzidos durante a formação dos ácidos acético e butírico. Os ácidos graxos voláteis representam a principal fonte energética dos ruminantes, todavia, a amônia, o $\mathrm{CO}_{2}$ e o $\mathrm{CH}_{4}$ representam perdas de nitrogênio e de energia, respectivamente. Um fato importante é que as bactérias gram-positivas são responsáveis pela maior produção de $\mathrm{NH}_{3}$, como as Clostridium e Peptostreptococus; de lactato, como as Streptococcus e Lactobacillus; dos ácidos acético e butírico, como as Butyrivibrio, Ruminococcus e Fibrobacter; e de $\mathrm{CO}_{2}$ e $\mathrm{CH}_{4}$. As bactérias gramnegativas são responsáveis pela maior produção de ácido propiônico, a exemplo das Bacterioides, Selenomonas e Veillonella, e pelo maior consumo de 1actato, como as Anaerovibrio, Megasfera e Selenomonas (Chen \& Wollin, 1979; Dennis et al., 1981; Richardson, 1990; Tung \& Kung, 1993; Russell, 1996; Plaizier et al., 1997).

Como os ionóforos atuam selecionando as bactérias gram-negativas (Russell \& Wallace, 1997), há aumento da porcentagem molar do ácido propiônico (Badawy et al., 1996), seguido por elevação dos níveis de glicose sanguínea (Maas et al., 2001), diminuição dos ácidos acético e butírico (McGuffey et al., 2001) e da concentração de amônia, com posterior aumento do aporte de aminoácidos digeridos e absorvidos diretamente no intestino delgado (Russell \& Strobel, 1989; Hegazy \& Elias, 1997) e diminuição de lactato (Dennis et al., 1981; Russell \& Strobel, 1989), com conseqüente elevação do pH ruminal (Russell, 1996). Desse modo, ocorre aumento da energia metabolizável em função da redução da produção de $\mathrm{CO}_{2}$ e $\mathrm{CH}_{4}$ (Bagg, 1997) e maior eficiência metabólica na utilização do propionato, uma vez que ele é o único ácido graxo volátil utilizado para síntese de glicose no fígado e tem possibilidade de ser oxidado diretamente no Ciclo de Krebs (Schelling, 1984). Outra vantagem proporcionada pelos ionóforos é a melhoria na digestibilidade (Wedegaertner \& Johnson, 1983), em razão do menor consumo decorrente do maior tempo de permanência do alimento no trato digestivo e, possivelmente, da maior secreção de insulina ocasionada indiretamente pela monensina, via aumento de propionato e glicose sanguínea (Cinar \& Sulu, 1995; Hegazy, 1997), com conseqüente estímulo e aumento das secreções dos principais hormônios gastrintestinais (gastrina, secretina, colecistoquinina e peptídeo gastrointestinal - GIP) responsáveis pelo processo de digestão (Teixeira, 1996).

A digestibilidade, definida como a fração do nutriente ingerido que não é recuperado nas fezes, constitui-se em um método indispensável para a avaliação dos alimentos e tem sido amplamente estudada em ruminantes. A determinação da digestibilidade de um alimento compreende a medida quantitativa dos nutrientes consumidos e das quantidades excretadas nas fezes. Como a coleta total de fezes para a verificação da digestibilidade em bovinos é trabalhosa, formas indiretas para determinação da produção de fezes, por meio do uso de indicadores, têm sido sugeridas por autores como Coelho da Silva \& Leão (1979) e Prigge et al. (1981). A fibra em detergente ácido indigestível (FDAi) também tem se destacado como um bom 
indicador interno, estando intimamente associada ao alimento e permanecendo uniformemente distribuída na digesta, o que permite boa estimativa da produção fecal (Craig et al., 1984).

Desse modo, o objetivo neste experimento foi avaliar a influência da inclusão de diferentes níveis da monensina sódica na dieta sobre os parâmetros ruminal, sangüíneo e urinário e a digestibilidade aparente em novilhas leiteiras confinadas.

\section{Material e Métodos}

O experimento foi executado no Setor de Gado de Leite e as análises químicas foram realizadas nos Laboratórios de Microbiologia, Química, Veterinária e Nutrição Animal, pertencentes à Universidade Federal de Viçosa, em Viçosa - MG. Foram utilizadas 28 novilhas da raça Holandesa (quatro PO, duas 15/16 e uma 7/8) por tratamento, com pesos vivos médios inicial e final de 245,0 e $336,8 \mathrm{~kg}$, respectivamente.

Os animais permaneceram confinados em baias individuais, em um galpão de alvenaria, onde receberam dietas constituídas de $33,58 \%$ de silagem de milho, $33,58 \%$ de cana-de-açúcar e $32,84 \%$ de concentrado, composto por grão de milho, farelo de soja, uréia e mistura mineral, com base na matéria seca (Tabela 1). O experimento durou 104 dias (20 para adaptação e três períodos de 28 dias para verificação do desempenho). Todas as dietas eram isoprotéicas e isoenergéticas e apresentavam $15,5 \%$ de proteína bruta (PB) e $68 \%$ de nutrientes digestíveis totais (NDT). Os alimentos foram fornecidos na forma de ração completa, em duas refeições diárias, às 7 e $17 \mathrm{~h}$. Os níveis de ionóforo avaliados foram 0, 14, 28 e 42 $\mathrm{mg}$ de monensina/kg de MS da dieta, misturados no concentrado, totalizando quatro tratamentos com sete repetições. Após o período de avaliação do desempenho, as novilhas permaneceram confinadas por mais uma semana, recebendo as mesmas dietas, para a realização das coletas (duas de líquido ruminal, uma de sangue e uma de urina).

A coleta de líquido ruminal foi realizada imediatamente antes e 2 horas após a primeira refeição diária, utilizando-se uma sonda esofágica acoplada a uma bomba de vácuo. Imediatamente após a coleta, o líquido ruminal foi filtrado em quatro camadas de gaze, determinando-se o $\mathrm{pH}$, por meio de um peagâmetro. A seguir, as amostras de líquido ruminal foram resfriadas com gelo e transportadas para o laboratório, para as análises dos teores de amônia e dos ácidos graxos voláteis (acético, propiônico e butírico). A concentração de amônia foi determinada segundo o método colorimétrico, descrito por Chaney \& Marbach (1962) e adaptado ao Laboratório de Microbiologia - UFV (Oliveira, 2003), e as análises dos teores de ácidos graxos voláteis foram realizadas por cromatografia gasosa, segundo o método proposto por Erwin et al. (1961) e adaptado pelo Laboratório de Química - UFV (Oliveira, 2003).

Tabela 1- Composição percentual dos ingredientes e teores de proteína bruta, nutrientes digestíveis totais, cálcio e fósforo das dietas experimentais, expressos na matéria seca

Table 1 - Ingredient composition and contents of and crude protein, total digestible nutrients, calcium and phosphorus of the experimental diets, in dry matter basis

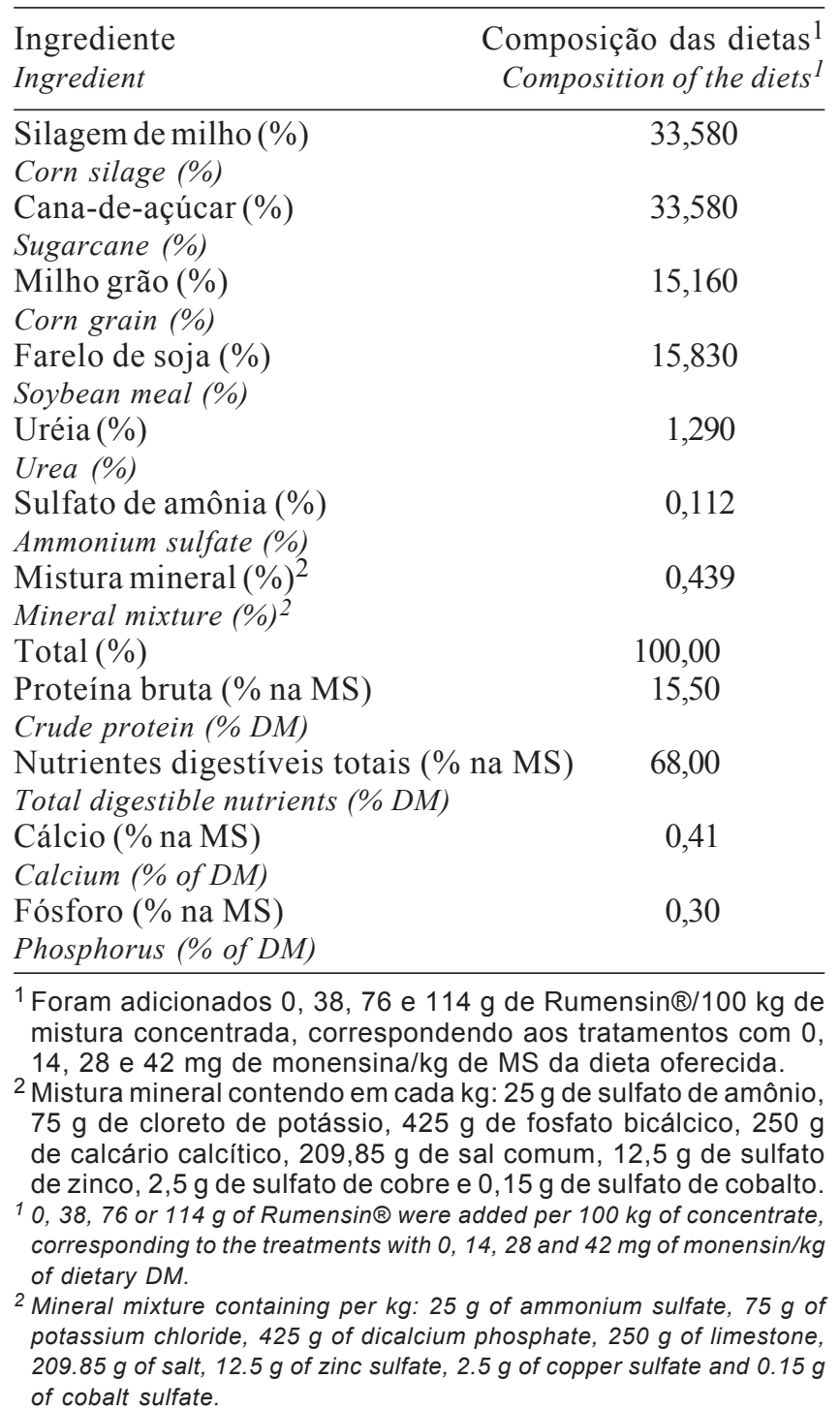


O sangue foi coletado diretamente na veia jugular 2 horas após a refeição, simultaneamente com a coleta de líquido ruminal, utilizando-se tubos de vacuntainer contendo duas gotas de heparina para impedir a coagulação do sangue. As amostras foram imediatamente centrifugadas e o plasma congelado. Posteriormente, as análises de glicose e uréia foram feitas no Laboratório de Veterinária - UFV, utilizando-se kits comerciais, sendo a leitura feita em espectofotômetro. A coleta da amostra de urina também foi feita 2 horas após a refeição, por meio de massagem da região abaixo da vulva. Após a determinação da concentração de creatinina e uréia na amostra de urina (Laboratório de Veterinária - UFV, utilizando-se kits comerciais e leitura em espectofotômetro), calculou-se a produção urinária a partir da fórmula: Produção de urina = [(27,77 mg creatinina $\mathrm{x}$ Peso vivo)/Concentração de creatinina na amostra em mg/litro], descrita por Rennó (2003), que trabalhou com novilhos em crescimento das raças Holandês, Girolando e Zebu. Posteriormente, calculou-se a perda de uréia na urina, expressa em $\mathrm{g} / \mathrm{dia}, \mathrm{mg} / \mathrm{kg}$ de peso vivo (PV) e mg N-uréia/kg de PV, por meio das equações: $\{[(\mathrm{mg} / \mathrm{dl}$ de uréia na amostra de urina x 10) x litros de urina $] / 1000\} ;$ [(mg/dia de uréia)/peso vivo]; e ( $\mathrm{mg} / \mathrm{kg}$ de PV de uréia x 0,466), respectivamente.

A influência da monensina sobre a digestibilidade foi avaliada entre a $2^{\underline{a}}$ e a $3^{\underline{a}}$ semanas do segundo período experimental, utilizando-se a forma indireta. Durante dez dias, foram coletadas e congeladas amostras dos alimentos oferecidos e das sobras de cada novilha, elaborando-se uma amostra composta do período para cada animal. Também foram realizadas duas coletas de fezes diretamente no reto dos animais: a primeira pela manhã, no $3 \underline{a}$ dia após o início da verificação da digestibilidade, e a $2^{\underline{a}}$, após um intervalo de sete dias, à tarde. Essas amostras também foram congeladas e, posteriormente processadas. A produção fecal foi estimada utilizando-se a fibra em detergente ácido indigestível (FDAi) como indicador interno. Foram incubados os alimentos oferecidos, as sobras e as fezes $(0,5 \mathrm{~g}$ de amostra, moída em peneira de $1 \mathrm{~mm}$, por saco - Ankom) no rúmen de um bovino Holandês por 144 horas. Os sacos Ankom foram posteriormente lavados em água corrente e, em seguida, em solução de detergente ácido, segundo o método descrito por Craig et al. (1984) e adaptado pelo Laboratório de Nutrição Animal - UFV. Foram calculados os teores de MS, matéria orgânica (MO), proteína bruta $(\mathrm{PB})$, extrato etéreo $(\mathrm{EE})$, cinzas $(\mathrm{CZ})$ e fibra em detergente neutro (FDN), no Laboratório de Nutrição Animal - UFV, conforme os procedimentos descritos por Silva (1990); e de carboidratos totais (CHOT) e NDT, segundo metodologia descrita por Sniffen et al. (1992). Já a FDAi foi determinada segundo os procedimentos descritos por Craig et al. (1984).

O delineamento utilizado foi inteiramente casualizado, com quatro tratamentos e sete repetições, sendo realizados estudos de regressão e contrastes ortogonais, por meio do pacote estatístico SAS (1997). O modelo estatístico utilizado foi:

$$
Y_{i j}=m+T_{i}+e_{i j}
$$

em que $Y_{i j}=$ observação referente ao animal ${ }_{j}$ recebendo o tratamento ${ }_{i} ; \mathrm{m}=$ constante geral; $\mathrm{T}_{\mathrm{i}}=$ efeito do tratamento $\mathrm{i}, \mathrm{i}=1,2,3$ e $4\left(\mathrm{i}_{1}=0, \mathrm{i}_{2}=14\right.$, $\mathrm{i}_{3}=28$ e $\mathrm{i}_{4}=42 \mathrm{mg}$ de monensina $/ \mathrm{kg}$ de MS da ração); e $\mathrm{e}_{\mathrm{ij}}=$ erro aleatório associado a cada observação.

Nos estudos de regressão, foram testados os modelos linear, quadrático e cúbico. O coeficiente de determinação $\left(\mathrm{r}^{2}\right)$ foi calculado manualmente segundo a equação: $r^{2}=$ (SQRLinear/SQTotal; SQRQuadrática/ SQTotal; e SQRCúbica/SQTotal, para os coeficientes de determinação linear, quadrático e cúbico, respectivamente). Nos estudos de contrastes, testou-se o tratamento sem monensina em relação aos tratamentos com monensina (14, 28 e 42 mg/kg MS de ração).

\section{Resultados e Discussão}

$\mathrm{Na}$ Tabela 2 encontram-se os valores de $\mathrm{pH}$, amônia, ácidos acético, propiônico e butírico e a relação acetato:propionato, com suas respectivas equações de regressão em função dos tratamentos contendo $0,14,28$ e $42 \mathrm{mg}$ de monensina. Na Tabela 3 são apresentadas as variáveis amônia e ácido propiônico e a relação acetato: propionato, analisadas por contrastes ortogonais, comparando-se o tratamento sem monensina com os demais.

O pH ruminal pode variar de 4,5 a 7,0 dependendo da dieta fornecida ao animal. Quando são ofertadas grandes quantidades de grãos, a elevada taxa de fermentação pode diminuir o $\mathrm{pH}$, favorecendo o desenvolvimento de bactérias produtoras de ácido láctico, havendo acúmulo de lactato no fluido ruminal e, conseqüentemente, severa diminuição do $\mathrm{pH}$, além de sintomas de acidose (Hungate, 1966). Nestes casos, a monensina pode ajudar a restaurar o $\mathrm{pH}$ ruminal, uma vez que ela diminui a produção de lactato por 
Tabela 2 - Valores de pH, amônia, ácidos acético, propiônico e butírico e relação acetato:propionato do líquido ruminal, às 0 e 2 horas após a refeição, e equações de regressão significativas, em novilhas leiteiras recebendo dietas com diversos níveis de monensina

Table 2 - Ruminal values of $\mathrm{pH}$, ammonia, acetate, propionate and butyrate acids, and the acetate: propionate ratio before feeding and 2 hours after feeding, and the significant regression equations in dairy heifers receiving diets with different levels of monensin

Item $\quad$ Nível de monensina (mg/kg MS dieta) $\quad \mathrm{CV}^{1}$

Level of monensin ( $\mathrm{mg} / \mathrm{kg}$ diet dry matter)

$(\%)$

$\begin{array}{llll}0 & 14 & 28\end{array}$

Imediatamente antes da refeição

Immediately beforefeeding

$\mathrm{pH}$

Amônia - mg/dL

Ammonia - $m g / d L$

Ácido acético - mmol/L

Acetate - $\mathrm{mmol} / \mathrm{L}$

Ácido propiônico - mmol/L

Propionate - $\mathrm{mmol} / \mathrm{L}$

Ácido butírico - mmol/L

Butyrate - $\mathrm{mmol} / \mathrm{L}$

Relação acetato:propionato

Acetate:propionate ratio

2 horas após refeição

2 hour after feeding

$\mathrm{pH}$

Amônia-mg/dL

Ammonia - mg/DL

Ácido acético - $\mathrm{mmol} / \mathrm{L}$

Acetate - $\mathrm{mmol} / \mathrm{L}$

Ácido propiônico - mmol/L

Propionate - $\mathrm{mmol} / \mathrm{L}$

Ácido butírico - mmol/L

Butyrate - $\mathrm{mmol} / \mathrm{L}$

Relação acetato:propionato

Acetate:propionateratio

$\begin{array}{rrrrr}7,23 & 7,20 & 7,19 & 7,19 & 2,36 \\ 9,38 & 6,10 & 7,56 & 6,26 & 43,23 \\ 73,96 & 68,17 & 70,48 & 62,69 & 17,24 \\ 14,65 & 15,34 & 16,77 & 15,05 & 22,24 \\ 6,16 & 6,19 & 5,70 & 6,65 & 30,47 \\ 5,05 & 4,44 & 4,20 & 4,16 & 22,04\end{array}$

\begin{tabular}{lccc}
\hline & $\begin{array}{c}\text { Equação de regressão } \\
\text { Regression equation }^{2}\end{array}$ & $\begin{array}{c}\text { Probabilidade } \\
\text { Probability }^{2}\end{array}$ & $\mathrm{r}^{2}$ \\
$\begin{array}{l}\text { Imediatamente antes da refeição } \\
\begin{array}{l}\text { Immediately beforefeeding } \\
\text { Relação acetato: propionato } \\
\text { Acetate:propionate ratio }\end{array}\end{array}$ & $\hat{\mathrm{Y}}=5,078286-0,021857^{*} \mathrm{X}$ & 0,0872 & 10,84 \\
\hline
\end{tabular}

2 horas após refeição

2 hour after feeding

$\mathrm{pH}$

Ácido propiônico - mmol/L

$\hat{Y}=7,455714-0,008265 * X$

0,0170

20,02

Propionate - $\mathrm{mmol} / \mathrm{L}$

Relação Acetato: Propionato

$\hat{Y}=16,216286+0,092541 * X$

0,0375

15,61

Acetate: Propionate ratio

$\hat{Y}=4,688286-0,029153 * X$

0,0005

37,77

${ }^{1} \mathrm{CV}$ : Coeficiente de variação (Coefficient of variation).

2 X: Nível de monensina ( $\mathrm{mg} / \mathrm{kg}$ MS na dieta) (X: Level of monensin [mg/kg of diet dry matter]).

meio da inibição do crescimento do Streptococcus bovis, principal bactéria causadora da acidose láctica (Suda et al., 1995; Russell, 1996; Zhou \& Clark, 1999). Todavia, em dietas com alta proporção de volumoso, pouca vantagem tem sido notificada em relação à variável $\mathrm{pH}$, quando a monensina é fornecida aos ruminantes (Mousa, 1994; Haimoud et al., 1995; Hegazy \& Elias, 1997; Garcia et al., 2000).

Neste experimento, como $67 \%$ da dieta era composta por volumosos, a adição de monensina não promoveu alteração do $\mathrm{pH}$ ruminal, mantendo-se estável no tempo zero, com média de 7,2. Apesar de 
Tabela 3 - Comparação das variáveis amônia, ácido propiônico e relação acetato:propionato do líquido ruminal às 0 e 2 horas após a refeição, por meio da análise de contrastes ortogonais, referente aos tratamentos contendo $0,14,28$ e $42 \mathrm{mg}$ de monensina/kg MS da dieta

Table 3 - Comparison of the ruminal concentration of ammonia and acetate, and the acetate: propionate ratio before feeding and

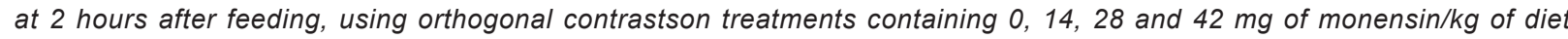
dry matter

\begin{tabular}{|c|c|c|c|c|}
\hline $\begin{array}{l}\text { Contraste }-0 \text { vs } 14,28 \text { e } 42 \mathrm{mg} \\
\text { Contrast }-0 \text { vs } 14,28 \text { and } 42 \mathrm{mg}\end{array}$ & $\begin{array}{l}\text { Grau de liberdade } \\
\text { Degree of freedom }\end{array}$ & $\begin{array}{l}\text { Quadrado médio } \\
\text { Mean square }\end{array}$ & $\begin{array}{l}\text { Valor } \mathrm{F} \\
\text { F value }\end{array}$ & $\begin{array}{c}\text { Probabilidade } \\
\text { Probability } \\
\end{array}$ \\
\hline $\begin{array}{l}\text { Amônia - mg/dL - } 0 \mathrm{~h} \\
\text { Ammonia }-m g / d L-0 h\end{array}$ & 1 & 13,5876 & 4,02 & 0,0565 \\
\hline $\begin{array}{l}\text { Ác. Propiônico }-\mathrm{m} \mathrm{mol} / \mathrm{L}-2 \mathrm{~h} \\
\text { Propionate }-\mathrm{m} \mathrm{mol} / \mathrm{L}-2 \mathrm{~h}\end{array}$ & 1 & 71,0056 & 6,03 & 0,0217 \\
\hline $\begin{array}{l}\text { Acetato: Propionato }-2 \mathrm{~h} \\
\text { Acetate:Propionate }-2 \mathrm{~h}\end{array}$ & 1 & 4,5128 & 12,65 & 0,0016 \\
\hline
\end{tabular}

elevado $(7,46$ a 7,16), verificou-se também uma diminuição linear do $\mathrm{pH}$ na coleta realizada 2 horas após a refeição com o aumento do nível de monensina na dieta. Possivelmente, esses valores de $\mathrm{pH}$ superiores a 7 indiquem uma pequena contaminação com saliva, ocasionada pelo método de coleta utilizado. Lana \& Russell (1997) também verificaram reduções no pH ruminal ao fornecerem monensina a vacas nãolactantes alimentadas com feno de timóteo e/ou alfafa. Analogamente, Zinn et al. (1994), ao fornecerem monensina a bovinos confinados, também verificaram queda no $\mathrm{pH}$ ruminal.

A hidrólise de proteínas por enzimas microbianas ruminais libera peptídeos, que são quebrados em aminoácidos e amônia e incorporados como proteína microbiana. Quando a fermentação ultrapassa a capacidade de assimilação do nitrogênio pelos microrganismos, ocorre acúmulo de amônia e pequena retenção de nitrogênio pelo animal, sendo parte deste nitrogênio excretada pelos rins (AFRC, 1993). A redução da fermentação protéica pode ser feita com o uso de ionóforos, que diminui a degradação de peptídeos no rúmen, aumentando a quantidade de aminoácidos que chega ao intestino delgado (Russell \& Martin, 1984; Chen \& Russell, 1991; McGuffey et al., 2001).

A concentração de amônia também é dependente do $\mathrm{pH}$ ruminal, pois, quanto mais baixo o $\mathrm{pH}$, menor o nível de amônia (Erfle et al., 1982). Há, portanto, maior eficiência da monensina no controle da produção de amônia em dietas que proporcionam pHs mais altos (Lana et al., 1998). Como neste experimento o $\mathrm{pH}$ foi elevado (em média 7,2), esperava-se que a monensina promovesse diminuição da concentração de amônia ruminal, todavia, isto não foi observado (Tabela 2).
Redução significativa da concentração de amônia imediatamente antes da refeição foi verificada por meio da análise de contrastes ortogonais, na qual se comparou o líquido ruminal dos animais sem monensina com o daqueles que receberam monensina na dieta (Tabela 3). Reduções na concentração de amônia ruminal também foram observadas por Mousa (1994) e Salles \& Lucci (2000), em cabritos fistulados e bezerros holandeses, respectivamente, recebendo monensina na dieta. Plaizier et al. (2000), ao fornecerem monensina em cápsulas de liberação lenta a vacas leiteiras 60 dias antes do parto, também verificaram declínio na concentração de amônia ruminal.

Lana \& Russell (1997), por sua vez, não observaram queda na concentração de amônia quando monensina foi ofertada juntamente com $100 \%$ de feno de timóteo ou com a mistura dos fenos timóteo e alfafa (50:50). Similarmente, Lee et al. (1990) e Yalcin et al. (1995) também não verificaram mudanças na concentração de amônia ruminal em cordeiros da raça Merino e cabritos nativos da Coréia recebendo monensina na dieta.

Neste experimento, não foi verificada nenhuma mudança significativa na concentração de uréia no plasma sangüíneo com a adição de monensina na dieta das novilhas (Tabela 4). Similarmente, Badawy et al. (1996) e Hegazy (1997), ao fornecerem 150 e 200; e $100 \mathrm{mg}$ monensina/dia a búfalas antes e após o parto; e pré-púberes (10 a 14 meses de idade), respectivamente, não observaram mudanças no nível de uréia plasmática. Abe et al. (1994) e Plaizier et al. (2000) forneceram monensina em cápsula de liberação lenta para vacas leiteiras e Lee et al. (1990) a cabritos coreanos, alimentados com dietas contendo $80 \%$ de concentrado, e também não verificaram alterações no 
nível de uréia. Todavia, Hayes et al. (1996) e Duffield et al. (1998) estudaram vacas em regime de pastejo e novilhas leiteiras em primeira lactação, respectivamente, recebendo monensina em cápsula de liberação lenta e verificaram aumentos significativos no nível de uréia sangüínea. Mousa (1994), no entanto, ao fornecer monensina ( $10 \mathrm{mg} /$ dia $)$ a cabritos fistulados e observou diminuição da concentração de uréia sanguínea.

O suprimento energético dos ruminantes é proveniente principalmente dos ácidos graxos voláteis, dos quais o ácido propiônico o mais eficaz, pois diminui a energia que seria perdida com a fermentação até a formação dos gases $\mathrm{CH}_{4}$ e $\mathrm{CO}_{2}$, além de ser mais eficientemente utilizado pelos tecidos do corpo que o acetato e o butirato (Schelling, 1984). Como os ionóforos aumentam a proporção de ácido propiônico no rúmen, ocorre indiretamente, aumento da energia metabolizável dos alimentos (Bergen \& Bates, 1984) e, conseqüentemente, aumento da taxa de crescimento e uma resposta endócrina precoce, aparentemente influenciada pelos mecanismos reguladores da puberdade, em novilhas leiteiras (Medel et al., 1991).

Neste experimento, na coleta realizada 2 horas após a alimentação, verificou-se que a monensina contribuiu aumentando a proporção molar de ácido propiônico e diminuindo a relação acetato:propionato (Tabelas 2 e 3), o que está relacionado à capacidade da monensina em selecionar bactérias gram-negativas (Russell, 1996). Nesta coleta, a concentração de ácido propiônico elevou de 15,4 para 20,4 mmol/litro nos tratamentos com 0 e $28 \mathrm{mg}$ de monensina, respectivamente, ou seja, houve aumento de 32,5\%. Reduções lineares na relação acetato:propionato foram verificadas em ambos os horários de coleta. A análise de contrastes, na qual se comparou o tratamento controle com aqueles contendo monensina, novamente esses resultados foram confirmados, ou seja, a monensina promo- veu aumento da proporção de ácido propiônico e diminuição da relação acetato:propionato (Tabela 3).

Thammacharoen et al. (2001), ao fornecerem monensina em cápsulas de liberação lenta a vacas holandesas, também verificaram significativos aumentos na porcentagem molar de ácido propiônico e reduções na de ácido acético e na relação acetato:propionato, não sendo verificada diferença na porcentagem de ácido butírico. Do mesmo modo, Lee et al. (1990) e Mousa (1994), ao fornecerem monensina a cabritos, e Maas et al. (2001), a carneiros em regime de pastejo, verificaram aumento na concentração do ácido propiônico e diminuição dos ácidos acético e butírico e da relação acetato:propionato.

A elevação da proporção de ácido propiônico ruminal promove aumento do propionato hepático, que é o principal precursor da glicose sangüínea. Com isso, há redução dos aminoácidos que seriam destinados à gliconeogênese, com conseqüente aumento da disponibilidade de aminoácidos para a síntese de proteína.

Neste experimento, apesar do aumento da concentração de ácido propiônico ruminal, não foi possível detectar diferenças significativas no nível de glicose sanguínea entre os tratamentos (Tabela 4). Todavia, Mousa (1994) e Duffield et al. (1998) ao fornecerem monensina a cabritos fistulados e a novilhas leiteiras em primeira lactação, respectivamente, observaram aumentos significativos da concentração de glicose sanguínea. Hegazy (1997), por sua vez, forneceu 150 e $200 \mathrm{mg}$ monensina/dia a búfalas antes e após o parto e verificou que, além do aumento das concentrações plasmáticas de propionato e glicose, também houve elevação do nível de insulina circulante. No entanto, Granzin \& Dryden (1999) observaram que vacas no início da lactação recebendo $300 \mathrm{mg}$ de monensina/dia não apresentaram alterações no nível de insulina, apesar de ter havido significativa diminuição na proporção

Tabela 4 - Valores de glicose e uréia sangüínea, em novilhas leiteiras recebendo dietas com diferentes níveis de monensina

Table 4 - Contents of blood glucose and urea in dairy heifers receiving diets with different levels of monensin

\begin{tabular}{|c|c|c|c|c|c|c|}
\hline \multirow[t]{2}{*}{ Item } & \multicolumn{4}{|c|}{$\begin{array}{l}\text { Nível de monensina ( } \mathrm{mg} / \mathrm{kg} \mathrm{MS} \text { da dieta) } \\
\text { Level of monensin ( } \mathrm{mg} / \mathrm{kg} \text { of diet dry matter) }\end{array}$} & \multirow[t]{2}{*}{$\begin{array}{l}\text { Probabilidade } \\
\text { Probability }\end{array}$} & \multirow[t]{2}{*}{$\mathrm{CV}$} \\
\hline & 0 & 14 & 28 & 42 & & \\
\hline $\begin{array}{l}\text { Glicose }-\mathrm{mg} / \mathrm{dL} \\
\text { Glucose }-m g / d L\end{array}$ & 83,77 & 84,07 & 90,09 & 84,27 & 0,6575 & 11,65 \\
\hline $\begin{array}{l}\text { Uréia - mg/dL } \\
\text { Urea }-m g / d L\end{array}$ & 41,00 & 41,01 & 43,61 & 39,34 & 0,7640 & 11,27 \\
\hline
\end{tabular}


molar de ácido acético e aumento do ácido propiônico ruminal e elevação do propionato hepático e dos níveis de glicose sanguínea. Yalcin et al. (1995), Badawy et al. (1996) e Salles et al. (2001) não verificaram mudanças na concentração de glicose em cordeiros da raça Merino, búfalas (10 a 14 meses de idade) e novilhas holandesas, respectivamente, recebendo monensina. Analogamente, Abe et al. (1994) e Hayes et al. (1996) forneceram a vacas leiteiras em regime de pastejo monensina em cápsula de liberação lenta e também não verificaram alterações nesta variável.

Além da mudança nos produtos finais da fermentação ruminal, quando se utilizam ionóforos, parte da melhoria no desempenho de bovinos confinados tem sido atribuída ao aumento da digestibilidade das dietas oferecidas aos animais (Wedegaertner \& Johnson, 1983; Medel et al., 1991), sendo este efeito geralmente associado à diminuição do consumo, que promove maior tempo de retenção dos alimentos no trato digestivo. No entanto, outros fatores indiretos, como o aumento do nível de insulina causado pela monensina via elevação de propionato hepático e, conseqüentemente, da glicose sanguínea, observados por Cinar \& Sulu (1995) e Hegazy (1997) também devem ser considerados, uma vez que os hormônios insulina e glucagon, segundo Teixeira (1996), estão também vinculados à liberação dos principais hormônios digestivos, como a gastrina, secretina, colicistoquina e GIP (peptídio gastrointestinal). Estes hormônios estimulam o abomaso, pâncreas, fígado (vesícula biliar), duodeno (glândulas de brünner) e intestino delgado (criptas de lieberkühn) a fazerem a secreção das enzimas digestivas (Swenson \& Reece, 1996). Aumentos significativos da atividade da enzima tripsina em carneiros, com a inclusão de monensina, já foram relatados por Rogers et al. (1991).

Na Tabela 5 estão descritos os consumos de MS, MO, PB, EE, CHOT, FDN e NDT; e os teores de

Tabela 5 - Consumo de matéria seca, expresso em kg/dia (CMS), em porcentagem do peso vivo (CMSPV) e em função do peso metabólico (CMSPM); consumos de matéria orgânica (CMO), proteína bruta (CPB), extrato etéreo (CEE), carboidratos totais (CCHOT), fibra em detergente neutro (CFDN), nutrientes digestíveis totais (CNDT); e teores de NDT e energia digestível (ED), em novilhas leiteiras recebendo dietas com diferentes níveis de monensina

Table 5 - Dry matter intake, expressed in kg/day (DMI), in percentage of the body weight (DMIBW) and in metabolic weight (DMIMW); intakes of organic matter (OMI), crude protein (CPI), ether extract (EEI), total carbohydrate (TCI), neutral detergent fiber (NDFI), total digestible nutrients (TDNI), and contents of TDN and digestible energy (DE) in dairy heifers receiving diets with different levels of monensin

\begin{tabular}{|c|c|c|c|c|c|c|}
\hline \multirow[t]{2}{*}{ Item } & \multicolumn{4}{|c|}{$\begin{array}{l}\text { Nível de monensina ( } \mathrm{mg} / \mathrm{kg} \text { MS da dieta) } \\
\text { Level of monensin (mg/kg of diet dry matter) }\end{array}$} & \multirow[t]{2}{*}{$\begin{array}{l}\text { Probabilidade } \\
\text { Probability }\end{array}$} & \multirow[t]{2}{*}{$\mathrm{CV}$} \\
\hline & 0 & 14 & 28 & 42 & & \\
\hline $\begin{array}{l}\text { CMS - kg MS/animal/dia } \\
\text { DMI - kg DM/animal/day }\end{array}$ & 7,29 & 7,14 & 7,06 & 7,15 & 0,8096 & 16,09 \\
\hline $\begin{array}{l}\text { CMSPV - } \mathrm{kg} M S / 100 \mathrm{~kg} \text { peso vivo } \\
D M I B W-\mathrm{kg} D M / 100 \mathrm{~kg} \text { of } B W\end{array}$ & 2,42 & 2,44 & 2,34 & 2,39 & 0,7026 & 11,33 \\
\hline $\begin{array}{l}\text { CMSPM - g MS/(PV })^{0,75} \\
D M I M W-g D M /(B W)^{0.75}\end{array}$ & 100,35 & 100,52 & 96,94 & 98,92 & 0,5890 & 8,58 \\
\hline $\begin{array}{l}\mathrm{CMO}-\mathrm{kg} / \mathrm{dia} \\
O M I-\mathrm{kg} / \mathrm{day}\end{array}$ & 7,01 & 6,24 & 6,46 & 6,88 & 0,9439 & 19,68 \\
\hline $\begin{array}{l}\text { CPB }-\mathrm{kg} / \mathrm{dia} \\
C P I-\mathrm{kg} / \text { day }\end{array}$ & 1,11 & 1,00 & 1,05 & 1,10 & 0,9727 & 18,36 \\
\hline $\begin{array}{l}\mathrm{CEE}-\mathrm{kg} / \mathrm{dia} \\
E E I-\mathrm{kg} / \text { day }\end{array}$ & 0,15 & 0,14 & 0,15 & 0,15 & 0,8619 & 19,51 \\
\hline $\begin{array}{l}\text { CCHOT }-\mathrm{kg} / \mathrm{dia} \\
T C I-\mathrm{kg} / \mathrm{day}\end{array}$ & 5,75 & 5,10 & 5,27 & 5,63 & 0,9216 & 20,02 \\
\hline $\begin{array}{l}\text { CFDN }-\mathrm{kg} / \mathrm{dia} \\
N D F I-\mathrm{kg} / \text { day }\end{array}$ & 2,20 & 2,01 & 1,98 & 2,14 & 0,7593 & 19,27 \\
\hline $\begin{array}{l}\text { CNDT }-\mathrm{kg} / \mathrm{dia} \\
T D N I-\mathrm{kg} / \text { day }\end{array}$ & 4,42 & 4,11 & 4,37 & 4,43 & 0,8337 & 17,75 \\
\hline $\begin{array}{l}\% \text { NDT na dieta } \\
\% \text { TDN in the diet }\end{array}$ & 60,93 & 61,48 & 62,75 & 62,27 & 0,6165 & 10,02 \\
\hline $\begin{array}{l}\mathrm{ED}-\mathrm{kcal} / \mathrm{g} \mathrm{MS} \\
D E-\text { kcal/grams of } D M\end{array}$ & 2,69 & 2,71 & 2,77 & 2,75 & 0,6264 & 10,00 \\
\hline
\end{tabular}

*ED: $(\% N D T / 100)$ * 4,409, segundo NRC (2001). 
NDT e energia digestível (ED) dos tratamentos contendo $0,14,28$ e $42 \mathrm{mg}$ de monensina/kg de MS, referentes a $2^{\underline{a}}$ e $3 \underline{a}$ semanas do segundo período de avaliação do desempenho das novilhas.

Não foram verificadas diferenças significativas nos consumos, independentemente do nível de monensina fornecido. Zinn et al. (1994) e Garcia et al. (2000), ao fornecerem monensina a bovinos confinados e a carneiros fistulados da raça Sufolk, respectivamente, também não observaram diferenças no consumo. Todavia, Lee et al. (1990), ao fornecerem monensina $(0,22$ ou $33 \mathrm{mg} / \mathrm{kg}$ MS $)$ a cabritos nativos da Coréia, constataram diminuições significativas no consumo de matéria seca. Patil \& Honmode (1994), ao ofertarem a cordeiros da raça Malpura 0, 11 e 22 $\mathrm{mg}$ de monensina/kg MS na dieta, observaram diminuição linear do consumo de concentrado com o aumento de monensina, enquanto o consumo de volumoso aumentou nos animais que receberam monensina.

Na Tabela 6 estão descritas as digestibilidades da MS, MO, PB, EE, CHOT e FDN, com as respectivas equações de regressão, em função dos tratamentos. As digestibilidades da MS, EE e CHOT apresentaram diferenças significativas nos níveis de 7, 8 e 9\% de probabilidade, respectivamente, porém, com resposta quadrática, ou seja, houve melhoria na digestibilidade até o nível de $28 \mathrm{mg}$ e posterior redução no nível de $42 \mathrm{mg}$.

Analogamente, Lee et al. (1990) e Su et al. (1993), ao fornecerem a cabritos 0,22 ou 33; e 0,15 e $30 \mathrm{mg}$ de monensina/kg MS da dieta, respectivamente, também verificaram melhoria na digestibilidade nos animais que receberam 22 e $15 \mathrm{mg}$ de monensina, respectivamente. No entanto, os níveis de 33 e $30 \mathrm{mg}$, respectivamente, promoveram piora na digestibilidade. Todavia, Salles \& Lucci (2000), ao fornecerem 0; 0,4; 0,8; e 1,2 mg de monensina/kg de PV a bezerros holandeses, verificaram que a monensina aumentou linearmente o coeficiente de digestibilidade aparente da MS (59,34; $60,47 ; 62,37$ e $66,38 \%)$; PB $(73,56 ; 75,07 ; 75,92$ е $78,31 \%)$; e FDN $(30,64 ; 31,92 ; 35,84$ e $43,72 \%)$, respectivamente. Patil \& Honmode (1994) ao fornecerem a cordeiros da raça Malpura 0,11 e $22 \mathrm{mg} / \mathrm{kg}$ MS da dieta, observaram que, com exceção da MS, que foi maior para os animais que receberam monensina, não houve diferenças na digestibilidade das demais variáveis.

Na Tabela 7 são comparados, por meio da análise de contrates ortogonais os animais que não receberam monensina com os demais. Observou-se novamente melhoria na digestibilidade da matéria seca e dos carboidratos totais nos animais que receberam monensina.

Araújo et al. (1991) verificaram que a monensina promoveu melhoria na digestibilidade da MS, da PB e da fibra em novilhos mestiços Holandês x Brahma alimentados com dietas contendo alto e baixo teores de fibra mais monensina e que esses resultados foram mais pronunciados nos animais alimentados com alta proporção de fibra na dieta. No entanto, Faulkner et al. (1985) relataram que a monensina não teve efeito

Tabela 6 - Digestibilidades da matéria seca (DigMS), matéria orgânica (DigMO), proteína bruta (DigPB), extrato etéreo (DigEE), carboidratos totais (DigCHOT) e fibra em detergente neutro (DigFDN), com as equações de regressão significativas, em novilhas leiteiras recebendo dietas com diferentes níveis de monensina

Table 6 - Digestibility of the dry matter (DigDM), organic matter (DigOM), crude protein (DigCP), ethereal extract (DigEE), total carbohydrates (DigTC), neutral detergent fiber(DigNDF) and the significant regression equations in dairy heifers receiving diets with different levels of monensin

\begin{tabular}{|c|c|c|c|c|c|}
\hline \multirow[t]{2}{*}{ Item } & \multicolumn{4}{|c|}{$\begin{array}{l}\text { Nível de monensina }(\mathrm{mg} / \mathrm{kg} \text { MS dieta) } \\
\text { Level of monensin }(\mathrm{mg} / \mathrm{kg} \text { diet dry matter) }\end{array}$} & \multirow[t]{2}{*}{$\begin{array}{l}\mathrm{CV} \\
(\%)\end{array}$} \\
\hline & 0 & 14 & 28 & 42 & \\
\hline DigMO - \% (DigOM - \%) & 61,26 & 62,89 & 65,45 & 62,84 & 5,47 \\
\hline DigPB - \% (DigCP - \%) & 65,78 & 66,88 & 70,92 & 67,50 & 6,28 \\
\hline DigEE - \% (DigEE - \%) & 72,00 & 75,52 & 78,28 & 68,25 & 10,15 \\
\hline \multirow[t]{2}{*}{ DigFDN - \% (DigNDF - \%) } & 28,22 & 29,42 & 29,50 & 28,17 & 16,09 \\
\hline & \multicolumn{3}{|c|}{$\begin{array}{l}\text { Equação de regressão }{ }^{1} \\
\text { Regression equation }\end{array}$} & $\begin{array}{l}\text { Probabilidade } \\
\text { Probability }\end{array}$ & $\mathrm{r}^{2}$ \\
\hline $\begin{array}{l}\text { DigMS (DigDM) } \\
\text { DigEE (DigEE) } \\
\text { DigCHOT }(\operatorname{Dig} T C)\end{array}$ & \multicolumn{3}{|c|}{$\begin{array}{l}\hat{Y}=61,505169+0,340699 * X-0,007987 * X^{2} \\
\hat{Y}=75,365708+0,439838 * X-0,014181 * X^{2} \\
\hat{Y}=62,198082+0,239660 * X-0,006115 * X^{2}\end{array}$} & $\begin{array}{l}0,0676 \\
0,0820 \\
0,0941\end{array}$ & $\begin{array}{l}14,41 \\
22,45 \\
13,28\end{array}$ \\
\hline
\end{tabular}

${ }_{1}^{1} \mathrm{X}$ : Nível de monensina ( $\mathrm{mg} / \mathrm{kg}$ MS na dieta).

${ }^{1}$ X: Level of monensin ( $\mathrm{mg} / \mathrm{kg}$ diet dry matter). 
Tabela 7- Comparação das variáveis digestibilidade da matéria seca (DigMS) e carboidratos totais (DigCHOT), por meio da análise de contrastes ortogonais, referente aos tratamentos contendo 0, 14, 28 e 42 mg de monensina

Table 7 - Comparison of apparent digestibilities of dry matter (DigDM) and total carbohydrates (DigTC) usinganalyses of orthogonal contrasts on treatments containing $0,14,28$ and $42 \mathrm{mg}$ of monensin

\begin{tabular}{lcccc}
\hline Contraste - 0 vs 14, 28 e $42 \mathrm{mg}$ & $\begin{array}{c}\text { Grau de liberdade } \\
\text { Degree of freedom }\end{array}$ & $\begin{array}{c}\text { Quadrado médio } \\
\text { Mean square }\end{array}$ & $\begin{array}{c}\text { Valor F } \\
\text { F Value }\end{array}$ & $\begin{array}{c}\text { Probabilidade } \\
\text { Probability }\end{array}$ \\
\hline $\begin{array}{l}\text { DigMS - \% } \\
\text { DigDM - \% }\end{array}$ & 1 & 67,0368 & 3,38 & 0,0783 \\
$\begin{array}{l}\text { DigCHOT - \% } \\
\text { DigTC - \% }\end{array}$ & 1 & 45,5113 & 3,00 & 0,0960 \\
\hline
\end{tabular}

sobre a digestibilidade de dietas com alto teor de fibra, ainda que o consumo de alimento fosse diminuído. Marounek et al. (1989), ao fornecerem monensina a bezerros, não verificaram diferenças na digestibilidade da MS, MO e PB, mas a digestibilidade do EE foi significativamente aumentada com a adição de monensina à dieta. Semelhantemente, Zinn et al. (1994), Garcia et al. (2000) e Vikram et al. (2001), ao fornecerem monensina a bovinos confinados, carneiros fistulados da raça Sufolk e a bezerros (3 a 12 meses), também não observaram diferenças na digestibilidade da MO, FDA e do amido, da MS e FDN, e de vários nutrientes, respectivamente.

Na Tabela 8 é descrita a perda de uréia pela urina, com suas respectivas equações de regressão, para os tratamentos contendo $0,14,28$ e $42 \mathrm{mg}$ de monensina. Verificou-se que o fornecimento de monensina pro- moveu redução na excreção de nitrogênio na urina (uréia e N-uréia, em mg/kg de PV) de forma quadrática.

Plaizier et al. (2000), ao fornecerem monensina em cápsula de liberação lenta a vacas leiteiras, verificaram, após o parto, aumento na digestibilidade aparente do nitrogênio de 63,7 para 71,5\%, que resultou em melhoria no balanço de nitrogênio de $-77,8$ para $-44,9 \mathrm{~g} /$ dia. Ruiz et al. (2001), ao fornecerem a vacas holandesas $350 \mathrm{mg}$ de monensina/dia/animal, também constataram aumento na digestibilidade aparente do nitrogênio de 5,4\%. De modo semelhante, Patil \& Honmode (1994) notaram que a retenção de nitrogênio foi maior nos animais que receberam $22 \mathrm{mg}$ de monensina, seguidos pelos animais que receberam 11 mg de monensina. Todavia, Lee et al. (1990) não observaram maior retenção de nitrogênio ao fornecerem monensina a cabritos.

Tabela 8 - Perda de uréia pela urina com as equações de regressão significativa, em novilhas leiteiras recebendo dietas contendo diferentes níveis de monensina

Table 8 - Urinary excretion of urea and its the significant regression equations in dairy heifers receiving diets with different levels of monensin

\begin{tabular}{|c|c|c|c|c|c|}
\hline \multirow[t]{2}{*}{ Item } & \multicolumn{4}{|c|}{$\begin{array}{l}\text { Nível de monensina ( } \mathrm{mg} / \mathrm{kg} \text { MS dieta) } \\
\text { Level of monensin (mg/kg diet dry matter) }\end{array}$} & \multirow[t]{2}{*}{$\begin{array}{l}\mathrm{CV}^{1} \\
(\%)\end{array}$} \\
\hline & 0 & 14 & 28 & 42 & \\
\hline $\begin{array}{l}\text { Uréia - g/dia (Urea - g/day) } \\
\text { Uréia - mg/kg PV (Urea - mg/kg BW) } \\
\text { N-uréia - mg/kg PV (N-urea - mg/kg BW) }\end{array}$ & $\begin{array}{l}227,62 \\
679,53 \\
316,66\end{array}$ & $\begin{array}{l}230,78 \\
698,21 \\
325,36\end{array}$ & $\begin{array}{l}222,37 \\
660,39 \\
307,74\end{array}$ & $\begin{array}{l}193,84 \\
576,54 \\
268,67\end{array}$ & $\begin{array}{l}20,13 \\
14,88 \\
15,10\end{array}$ \\
\hline N-uréia - mg/kg PV (N-urea - $m g / k g B W)$ & \multicolumn{3}{|c|}{$\begin{array}{c}\text { Equação de regressão } \\
\text { Regression equation }^{2}\end{array}$} & $\begin{array}{l}\text { Probabilidade } \\
\text { Probability }\end{array}$ & $r^{2}$ \\
\hline $\begin{array}{l}\text { Uréia - mg/kg PV (Urea - mg/kg } B W) \\
\text { N-uréia - mg/kg PV }(N \text {-urea }-m g / k g B W)\end{array}$ & \multicolumn{3}{|c|}{$\begin{array}{l}\hat{Y}=683,71600+2,726347 * X-0,115860 * X^{2} \\
\hat{Y}=316,90386+1,405276 * X-0,060944 * X^{2}\end{array}$} & $\begin{array}{l}0,0550 \\
0,0623\end{array}$ & $\begin{array}{l}14,37 \\
14,38\end{array}$ \\
\hline
\end{tabular}

${ }^{1} \mathrm{X}$ : Nível de monensina (mg/kg MS na dieta).

${ }^{1} X$ : Level of monensin ( $\mathrm{mg} / \mathrm{kg}$ of diet dry matter).

\section{Conclusões}

O fornecimento de monensina sódica a novilhas holandesas não influenciou o consumo e os níveis de glicose sanguínea. Entretanto, promoveu alterações nos produtos da fermentação ruminal, na digestibilidade e na perda de nitrogênio urinário. 


\section{Literatura Citada}

ABE, N.; LEAN, I.J.; RABIEE, A. et al. Effects of sodium monensin on reproductive performance of dairy cattle. II. Effects on metabolites in plasma, resumption of ovarian cyclicity and oestrus in lactating cows. Australian Veterinary Journal, v.71, n.9, p.277-282, 1994.

AGRICULTURAL AND FOOD RESEARCH COUNCIL AFRC. Energy and protein requirements of ruminants. Wallingford: CAB International, 1993. p.159.

ARAUJO F.O.; FERNANDEZ, M.C.; DEL, C.F.M. Efecto en novillos del monensin y el nivel de fibra de la dieta sobre el consumo y la digestibilidad de la materia seca. Revista de la Facultad de Agronomia, v.8, n.2, p.143-153, 1991.

BADAWY, S.A.; YOUNIS, M.; SHALASH, M.R. et al. Monensin effects on rumen metabolic profile, methane production and protozoal population in buffalo-heifers. Egyptian Journal of Veterinary Science, v.30, p.49-56, 1996.

BAGG, R. Mode of action of ionophores in lactating dairy cattle. Usefulness of ionophores in lactating dairy cattle. Proceedings of a Symposium Held at the Ontario Veterinary College, University of Guelph, p.13-21, 1997.

BERGEN, W.G.; BATES, D.B. Ionophores: their effect on production, efficiency and mode of action. Journal of Animal Science, v.58, p.1465-1483, 1984.

CHANEY, A.L.; MARBACH, E.P. Modified reagents for determination of urea and ammonia. Clinical Chemistry, v.8, p.130-132, 1962.

CHEN, M.; WOLLIN, M.J. Effect of monensin and lasalocidsodium on the growth of methanogenic and rumen saccharolytic bacteria. Applied Environment Microbiology, v.38, p.72-77, 1979.

CHEN, G.; RUSSELL, J.B. Effect of monensin and a protonophore on protein degradation, peptide accumulation, and deamination by mixed ruminal microorganisms in vitro. Journal of Animal Science, v.69, n.5, p.2196-2203, 1991.

CINAR, A; SULU, N. The effects of monensin on growth and development in calves. Turk Veterinerlik ve Hayvancilik Dergisi, v.19, n.6, p.381-389, 1995.

CRAIG, W.M.; HONG, B.J.; BRODERIC, G.A. et al. In vitro inoculum enriched with particle-associated microorganisms for determining rates of fiber digestion and protein degradation. Journal of Dairy Science, v.67, p.2902-2909, 1984.

DENNIS, S.M.; NAGARAJA, T.G.; BARTLEY, E.E. Effect of lasalocid or monensin on lactate-producing or using rumen bacteria. Journal of Animal Science, v.52, p.418-426, 1981.

DENNIS, S.M.; NAGARAJA, T.G.; DAYTON, A.D. Effect of lasalocid, monensin and thiopeptin on rumen protozoa. Research Veterinary Science, v.41, p.251-256, 1986.

DUFFIELD, T.F.; SANDALS, D.; LESLIE, K.E. et al. Effect of prepartum administration of monensin in a controlledrelease capsule on postpartum energy indicators in lactating dairy cows. Journal of Dairy Science, v.81, n.9, p.23542361, 1998.

ERFLE, J.D.; BOILA, R.J.; TEATHER, R.M. et al. Effect of pH on fermentation characteristics and protein degradation by rumen microorganisms in vitro. Journal of Dairy Science, n.65, p.1457-1464, 1982.

ERWIN, E.S.; MARCO, G.J.; EMERY, E.M. Volatile fatty acid analyses of blood and rumen fluid by gas chromatography. Journal of Dairy Science, v.44, n.9, p.1768-1771, 1961.
FAULKNER, D.B.; KLOPFENSTEIN, T.J.; TROTTER, T.N. et al. Monensin effects on digestibility, ruminal protein escape and microbial protein synthesis on high-fiber diets. Journal of Animal Science, v.61, p.654-660, 1985.

GARCIA, C.C.G.; MENDOZA, M.G.D.; GONZALEZ, M.S. et al. Effect of a yeast culture (Saccharomyces cerevisiae) and monensin on ruminal fermentation and digestion in sheep. Animal Feed Science and Technology, v.83, n.2, p.165$170,2000$.

GRANZIN, B.C.; DRYDEN, G.McL. The effects of monensin on milk production and levels of metabolites in blood and rumen fluid of Holstein-Friesian cows in early lactation. Australian Journal of Experimental Agriculture, v.39, n.8, p.933-940, 1999.

HAIMOUD, A.D.; VERNAY, M.; BAYOURTHE, C. et al. Avoparcin and monensin effects on the digestion of nutrients in dairy cows fed a mixed diet. Canadian Journal of Animal Science, v.75, n.3, p.379-385, 1995.

HANEY, Jr. M.E.; HOEHN, M.M. Monensin, a new biologically active compound. I. Discovery and isolation. Antimicrobial Agents Chemother, p.349, 1967.

HAYES, D.P.; PFEIFFER, D.U.; WILLIAMSON, N.B. Effect of intraruminal monensin capsules on reproductive performance and milk production of dairy cows fed pasture. Journal of Dairy Science, v.79, n.6, p.1000-1008, 1996.

HEGAZY, M.A. Influence of monensin on blood metabolite and reproductive performance of suckled buffalo-cows. Assiut Veterinary Medical Journal, v.36, n.72, p.313-325, 1997.

HEGAZY, M.A.; ELIAS, A.N. Influence of dietary monensin and lasalocid on age and weight of Barki ram and ewe lambs at puberty. Assiut Veterinary Medical Journal, v.37, n.74, p.1-15, 1997.

HUNGATE, R.E. The rumen and its microbes. New York: Academic Press, 1966. 533p.

LANA, R.P.; RUSSELL, J.B. Effect of forage quality and monensin on the ruminal fermentation of fistulated cows fed continuously at a constant intake. Dairy Forage Research Center, 1997. p.85-87. (Research Summaries)

LANA, R.P.; RUSSELL, J.B.; van AMBURGH, M.E. The role of $\mathrm{pH}$ in regulating ruminal methane and ammonia production. Journal of Animal Science, v.76, p.2190-2196, 1998.

LEE, S.K.; LEE, B.D.; JUNG, K.K. et al. Effect of feeding monensin on the feed intake, nutrient utilization and ruminal fermentation of Korean native goat. Korean Journal of Animal Sciences, v.32, n.2, p.74-82, 1990.

MAAS, J.A.; WILSON, G.F.; McCUTCHEON, S.N. et al. The effect of season and monensin sodium on the digestive characteristics of autumn and spring pasture fed to sheep. Journal of Animal Science, v.79, n.4, p.1052-1058, 2001.

MAROUNEK, M.; SKRIVANOVA, V.; MACHANOVA, L. Effect of monensin on digestibility of nutrients, ruminal volatile fatty acids and blood parameters in young calves. Landwirtschaftliche Forschung, v.42, n.4, p.273-280, 1989.

McGUFFEY, R.K.; RICHARDSON, L.F.; WILKINSON, J.I.D. Ionophores for dairy cattle: current status and future outlook. Journal of Dairy Science, v.84, Supplement, p.194-203, 2001.

MEDEL, M.; MERINO, P.; THOMAS, R. et al. Modo de acción del monensin en metabolismo ruminal y comportamiento animal. Ciencia e Investigación Agraria, v.18, n.3, p.153173,1991 
MOUSA, H.M. Ruminal and blood characteristics of Nubian goats dosed with the growth promoter monensin. Acta Veterinária Brno, v.63, n.1, p.13-17, 1994.

OLIVEIRA, M.V.M. Utilização do ionóforo monensina sódica na alimentação de ruminantes. Viçosa, MG: Universidade Federal de Viçosa, 2003. 110p. Tese (Doutorado em Zootecnia) - Universidade Federal de Viçosa, 2003.

PATIL, N.V.; HONMODE, J. Growth and nutrient utilisation in lambs as influenced by dietary monensin. Indian Journal of Animal Nutrition, v.11, n.4, p.237-239, 1994.

PLAIZIER, J.C.B.; GREEN, B.L.; McBRIDE, B.W. et al. Studies on the rumen physiology and metabolic function with pre-and postpartum administration of rumensin cre in the dairy cow. Usefulness of ionophores in lactating dairy cattle. Proceedings of a Symposium Held at the Ontario Veterinary College, 1997.

PLAIZIER, J.C.; MARTIN, A.; DUFFIELD, T. et al. Effect of a prepartum administration of monensin in a controlledrelease capsule on apparent digestibilities and nitrogen utilization in transition dairy cows. Journal of Dairy Science, v.83, n.12, p.2918-2925, 2000.

PRIGGE, E.C.; VARGA, G.A.; VICINI, J.L. et al. Comparison of ytterbium chloride and chromium sesquioxide as fecal indicator. Journal of Animal Science, v.53, n.6, p.16291633,1981 .

RENNO, L. Consumo, digestibilidade total e parcial, produção microbiana, parâmetros ruminais e excreções de uréia e creatinina em novilhos alimentados com dietas contendo quatro níveis de uréia ou dois níveis de proteína. Viçosa, MG: Universidade Federal de Viçosa, 2003. Tese (Doutorado em Zootecnia) - Universidade Federal de Viçosa, 2003.

RICHARDSON, L.F. Rumensin ${ }^{\circledR}$ : ruminal effects. Proceeding Symposium Rumensin ${ }^{\circledR}$ "in the 1990”, Dallas-Texas. Elanco Animal Health, Indianapolis, IN, 10 October, 1990. s.p.

ROGERS, M.; JOUANY, J.P.; THIVEND, P. et al. Comparative effects of feeding and duodenal infusion of monensin on digestion in sheep. Canadian Journal of Animal Science, v.71, n.4, p.1125-1133, 1991.

RUIZ, R.; ALBRECHT, G.L.; TEDESCHI, L.O. et al. Effect of monensin on the performance and nitrogen utilization of lactating dairy cows consuming fresh forage. Journal of Dairy Science, v.84, n.7, p.1717-1727, 2001

RUSSELL, J.B. Bacteria. Mechanisms of ionophore action in ruminal bacteria. Symposium Sponsored by: Elanco Animal Health. Scientific Update "On rumensin / Tylan/ Micotil for the professional feedlot consultant", Amarillo-TX, august, p.E1-E19, 1996.

RUSSELL, J.B.; MARTIN, S.A. Effects of various methane inhibitors on the fermentation of amino acids by mixed rumen microorganisms in vitro. Journal of Animal Science, v.59, p.1329-1338, 1984.

RUSSELL, J.B.; STROBEL, H.J. Mini review. Effect of ionofores on ruminal fermentation. Applied and Environmental Microbiology, v.55, p.1-6, 1989.

RUSSELL, J.B.; WALLACE, R.J. Energy-yielding and energyconsuming reactions. The rumen microbial ecosystem. 2.ed. 1997. p.267-268.

SALLES, M.S.V.; LUCCI, C.S. Monensina para bezerros ruminantes em crescimento acelerado. 2. Digestibilidade e parâmetros ruminais. Revista Brasileira de Zootecnia, v.29, n.2, p.582-588, 2000.
SALLES, M.S.V.; ZANETTI, M.A.; CONTI, R.M.C. et al. Efeitos da monensina no desempenho de bezerras leiteiras em crescimento. Revista Brasileira de Zootecnia, v.30, n.4, p.1293-1298, 2001.

SCHELLING, G.T. Monensin mode of action in the rumen. Journal of Animal Science, v.58, p.1518-1527, 1984.

SILVA, D.J. Análise de alimentos: métodos químicos e biológicos. 2.ed. Viçosa, MG:Universidade Federal de Viçosa, 1990. 165p.

SILVA, J.F.C.; LEÃO, M.I. Fundamentos de nutrição dos ruminantes. Piracicaba: Livroceres, 1979. 380p.

SNIFFEN, C.J.; O'CONNOR, J.D.; Van SOEST, P.J. et al. A net carbohydrate and protein system for evaluating cattle diets. II. Carbohydrate and protein availability. Journal of Animal Science, v.70, n.11, p.3562-3577, 1992.

STATISTIC ANALYSIS SYSTEM - SAS. User's guide. Cary: 1997. p.429.

SU, A.K.; YAN, S.S.; WU, S.C. Effect of monensin concentration in diets on growth performance and propionate concentration in the rumen of crossbred kids. Journal of Taiwan Livestock Research, v.26, n.4, p.297-306, 1993.

SUDA, K.; HIRAMATSU, M.; KOBAYASHI, Y. et al. Effects of ionophores on lactate and endotoxin production in the in vitro incubation of ruminal fluid. Animal Science and Technology, v.66, n.10, p.869-874, 1995.

SWENSON, M.J.; REECE, W.O. Dukes fisiologia dos animais domésticos. Rio de Janeiro: Guanabara, 1996. 856p.

THAMMACHAROEN, S.; CHANPONGSANG, S.; CHAIYABUTR, N. Effects of monensin administration on mammary function in late lactating crossbred Holstein cattle. Asian Australasian Journal of Animal Sciences, v.14, n.12, p.1712-1718, 2001.

TEIXEIRA, J.C. Fisiologia digestiva dos animais ruminantes. Lavras: UFLA/FAEPE, 1996. 260p.

TUNG, R.S.; KUNG Jr., L. In vitro effects of a thiopeptide and monensin in ruminal fermentation of soluble carbohydrates. Journal of Dairy Science, v.76, p.1083-1090, 1993.

VIKRAM, C.; RAMACHANDRA, B.; NAGABHUSHAN, V. et al. Effect of supplementation of monensin sodium on nutrient utilization in Deoni calves. Indian Veterinary Journal, v.78, n.7, p.611-614, 2001.

ZHOU, G.; CLARK, R.S. Effect of Rumensin and feed intake variation on ruminal $\mathrm{pH}$ in beef cattle. Journal of Jilin Agricultural University, v.21, n.4, p.1-5, 1999.

ZINN, R.A.; PLASCENCIA, A.; BARAJAS, R. Interaction of forage level and monensin in diets for feedlot cattle on growth performance and digestive function. Journal of Animal Science, v.72, n.9, p.2209-2215, 1994.

WEDEGAERTNER, T.C.; JOHNSON, D.E. Monensin effects on digestibility methanogenesis and heat increment of a cracked corn-silage diet fed to steers. Journal of Animal Science, v.57, p.168-177, 1983.

YALCIN, S.; KUCUKERSAN, K.; KUCUKERSAN, S. The effect of monensin added to the diet of fattening lambs on some blood and rumen fluid metabolites. Turk Veterinerlik ve Hayvancilik Dergisi, v.19, n.4, p.297-302, 1995.

Recebido em: 14/10/03 Aceito em: 07/07/05 